\title{
Toward a Theory of Restraint
}

\author{
Thomas Princen \\ University of Michigan
}

\begin{abstract}
Consumption largely remains a black box in the population, environment, and global change debates. The dominant perspective takes insatiability as axiomatic and assumes that reduced consumption will only happen through scarcity or the impositions of external authority. Yet humans often exhibit resource limiting behavior that is not the result of external controls nor is it altruistic or aberrant. This article develops the concept of restraint as an evolutionarily and culturally significant behavior, yet one that in modern times has been relegated to a regressive, if not trivial, status. The article defines restraint, hypothesizes its historical and evolutionary roots, lays out the conditions under which it can occur, and develops a theoretical parallel to cooperation in international relations theory.
\end{abstract}

\section{INTRODUCTION}

The population and environment nexus is becoming increasingly difficult to separate from the consumption and environment nexus. Activists have criticized the profligacy of western market economies and the waste of eastern command economies. International meetings such as the United Nations conferences on the environment and development in Rio in 1992 and on population and development in Cairo in 1994 have emphasized consumption along with sustainable development as central to reversing trends in environmental degradation. But movement beyond rhetoric has been problematic.

Please address correspondence to Dr. Princen, School of Natural Resources and Environment, Dana Building, The University of Michigan, Ann Arbor, MI 48109-1115.

Population and Environment: A Journal of Interdisciplinary Studies

Volume 18, Number 3, January 1997

(C) 1997 Human Sciences Press, Inc. 
Analytically, consumption has long been seen as a critical piece in the global change puzzle. But it has largely been treated in the aggregate, as a variable, for example, in the Ehrlich and Holdren formula, impact equals population times affluence times technology $(I=$ PAT $)$. Little attention has been paid to consumption, let alone decisions about levels of consumption, as a distinctive behavior. To be sure, marketing experts scrutinize individual and collective purchasing tendencies. Psychologists in the subfield of conservation behavior examine the motives for recycling, park attendance, and alternative transportation. And economists hold consumption as integral to both microeconomic and macroeconomic theory. But all these approaches to resource consumption have devoted little analytic attention, if any, to the behavioral underpinnings of reduced or limited resource consumption. What is more, little effort has been made to conceptualize alternative approaches.

Consumption or, more to the point, overconsumption, is thus one piece of the sustainability puzzle that largely remains a black box. Certainly environmentalists, development specialists, and others have identified overconsumption as a critical problem. But the dominant perspective that informs policymakers and citizens alike is that of economics where insatiability is taken as axiomatic, analytically and normatively. In fact, the very notion of progress and the belief in unending growth is premised on the inevitability and desirability of increasing consumption. For analysts and policy makers who do see consumption as a problem, there seems to be general agreement that reduced consumption will only happen through scarcity or the impositions of external authority. To do this, greed and lack of political will must be overcome. In the dominant belief system, if individuals and groups actually withhold immediate material consumption, it is seen as an oddity, as trivial instances of misguided altruism or hopelessly idealistic global citizenship. Such behavior is readily dismissed as the quaint habits of Amish farmers, the saintliness of Mother Teresa, or the anarchy of deep ecologists.

In this article, 1 argue that humans often exhibit resource limiting behavior that is distinct from such altruistic or aberrant behavior and yet, from an overall consumption or material throughput perspective, has comparable and potentially larger and more widespread consequences. This behavior I call restraint. I contend that restraint in material consumption is a distinct and identifiable behavior. What is more, this behavior and the conditions that foster it are worth investigating as a complement to externally imposed controls on population and regulations of economic activity.

I begin with the premise that consumers not only make tradeoffs among material goods and acquire resources to maximize survivability and 
reproductive success. But they also deliberately reduce or limit their material consumption in pursuit of nonmaterial benefits. The conditions under which they do this are critical, I argue, to both theory and policy aimed at ecological and social sustainability. The adaptive significance of restrained resource consumption, that is, the deliberate reduction in material benefits in exchange for nonmaterial benefits, enters the equation when humans shift to relatively sedentary and managed means of resource use.

This article develops the concept of restraint as an evolutionarily and culturally significant behavior, yet one that in modern times has been relegated to a regressive, if not trivial, sometimes revolutionary, status. To develop the argument, 1 define the concept, hypothesize its historical and evolutionary roots, and lay out the conditions under which it can occur. Finally, I argue that the inattention to restraint is analogous to the inattention to cooperation in international relations theory. My aim is to lay groundwork for a theory of restraint and for testing it empirically.

Before proceeding, it is important to distinguish restraint from what may appear to be comparable concepts-altruism, cooperation, and conservation. Altruism is self-sacrificing, other-interested behavior whereas restraint, as discussed below, refers to self-interested behavior. Instances of restraint can easily be interpreted as altruism but the individual's objectives that are of concern here include longterm economic security or the desire for group benefits, both of which conform better to a self-interest orientation. Although the group, society at large, and the planet as a whole may benefit from individuals' restraint, especially where resources are being depleted and alternatives are few, it does not follow that such individuals restrain their consumption for the larger good. Such behavior does occur but it is not the behavior I wish to examine. In part, this is because, as Low and Heinen (1993) argue from a behavioral ecology perspective, altruistic, other-interested behavior is a weak foundation for policy or educational goals when large-scale behavioral change is needed.

Cooperation and reciprocity are often associated with reduced resource use. But they are best viewed as necessary but not sufficient conditions for restraint. By themselves, they have no direction: actors can cooperate to conserve or to exploit, to reduce or to increase consumption. In international relations study, states are presumed to cooperate when they can overcome collective action problems (Olson, 1965) to achieve objectives mutually beneficial to state interésts (Keohane, 1984; Young, 1989). International tropical timber trade is almost a perfect example where, through the mutual formation of the International Tropical Timber Organization, producing and consuming states have cooperated to lower transaction costs, provide information, and facilitate trade. The problem, of 
course, is that with all this cooperation virtually none of the timber comes from sustainably managed forests (Poore, 1989). Restraint, by contrast, is explicit about the direction of resource use practices, denoting reduced or limited levels of consumption.

Conservation comes closest to restraint, especially when it refers to managed policies, programs and behaviors designed to limit or reduce the use of energy or materials or, say, wildlife. From the policy perspective, such conservation includes both formal laws and regulations and informal norms, beliefs and expectations. From the psychological perspective, conservation includes those behaviors associated with compliance with these formal and informal structures. The goal is less use of energy or materials or wildlife. Operational objectives include maintaining or restoring natural habitats, reducing dependence on foreign energy supplies, and reducing pollution. The desired behavior is individual action where the individual's expressed purpose is to use less. The motives can be intrinsic or extrinsic or both but the behavior requires both knowledge (generally arising externally) and explicit intent. The consumer must know that there is an energy problem or a wildlife problem and his or her action is aimed directly and solely at that problem. An endangered species policy (an external factor) along with environmental education makes the individual aware of and concerned about the threatened species. As a result, he or she uses less of the species or the habitat and the expressed purpose is to save the species, and only that; the purpose is not, for example, to provide for one's own needs.

Restraint is similar to conservation in that it refers to behavior that limits resource use. The reasons may also be intrinsic or extrinsic. But restraint is fundamentally associated with self-management, individual or collective behavior aimed at developing and maintaining a predictable and dependable support system. In its most basic form, restraint is behavior integral to survival, it is critical to self-maintenance, provisioning, and selfdefense. Its enactment, therefore, does not depend on external policies but on internal needs, that is, internal to, say, one's household or community or organization. Restraint occurs not because others say it is the right thing but because the very functioning of one's system requires it. And the effectiveness of that functioning increases with the compatibility between one's immediate environment (physical or social or both) and human actions, including restraint (Kaplan, 1983). Moreover, restraint occurs not because new, externally provided knowledge and concerns and incentives make it desirable, but because effective participation in one's system makes it imperative. The relevant system may be one's own subsistence farming, the 
THOMAS PRINCEN

common property management of an inshore fishery, or management of a privately owned corporation.'

In sum, the concept of restraint directs our analytic attention less to programs and external incentives and more to the full range of behaviors affecting human-environment interactions (Stern, 1993) and, especially, to those essential to survival. Thus, whereas conservation refers to individuals willingly and knowingly reducing consumption for the explicit purpose of conserving resources, restraint allows for reduction as a by-product of other motivations and activities. I can conserve by turning off my lights to save energy (or money); I can restrain my use of lights when they give me headaches by installing more windows. Restraint is therefore a more directed concept than altruism, cooperation, or conservation. Its analytic utility lies in its ability to disentangle these related behaviors to focus more directly on that behavior that leads to reduced or limited material resource consumption and that draws on human proclivities toward self-management, longterm security, and survival.

\section{RESTRAINT-A DEFINITION}

Restraint in resource consumption refers to an individual's choice to deliberately consume less material resources than what is possible in the immediate term, given available technologies. The choice of reduced material benefits is governed in part by the expectation of increased nonmaterial benefits. If I am the first to take the prey in a group hunt and I wait for the others before consuming it, I am exercising restraint. If I crave the seed corn or the immature shoots yet refrain from consuming them until the crops have matured, I am restraining my consumption. If I decide not to develop a parcel of land and instead donate it to the city for a park, 1 have restrained my consumption. If I manufacture a product that is a suspected carcinogen and unilaterally withdraw it from the market, I have exercised restraint. In all cases, I not only consume less of the good than is possible, but $I$ expect in return nonmaterial benefits such as group acceptance, reduced uncertainty (including uncertainty over long-run material consumption), enhanced personal health, and a reputation for civic mindedness.

Huastec forestry practices that have endured for centuries illustrate some of these characteristics. In a study of a typical Huastec community in Mexico, Alcorn and Toledo (1995) found that despite pressures on the Huastecs to log their forests and convert all their land to cash cropping and 
despite the relatively high population density, approximately $25 \%$ of the area is still forested although it could have been cleared. People chose not to clear it. The reasons they give for their decision to maintain biologically diverse managed forests include: commercially valuable products; direct access to products (firewood, fruits, medicine, construction materials and other items having use values); the option value of unknown products they may find useful in the future; the superior quality of life offered by fresh breezes, shade, clean water and clean air; protection of the Earth; and ecological services such as soil quality protection, prevention of erosion, and site improvement for swidden agriculture (p. 13).

With this definition and these illustrations in mind, the concept can be expanded by considering the sources of restraint, namely, economic calculation and social norms. With economic calculation, two behaviors need to be distinguished, both of which reduce consumption of a resource in a given time period. Substitution refers to the choice of one item over another; rather than eating one more apple, I choose an orange. In optimization terms, the marginal value of the orange is higher, even though, all told, I prefer apples. Relative to eating all apples, therefore, I have "reduced" my consumption of apples. From a resource perspective, however, I cannot say whether I have placed more or less ecological burden. With the marginal choice of the orange, I may certainly consume more resources overall. Restraint, by contrast, is behavior that reduces overall consumption in the relevant time period. Put differently, it is behavior that reduces immediate economic-i.e., material gain-for immediate or delayed, non-economic gain.

One way to conceive of the difference between substitution and restraint is to view restraint at the opposite end of a continuum from substitution (see Figure 1). The relevant dimension is material vs nonmaterial benefits. Points along the continuum represent tradeoff decisions that lead to the reduction in the consumption of an item. At the substitution end, the reduction is matched by increased consumption in another item, resulting in an ambiguous impact on overall resource use. At the restraint end, the reduction is matched by the enhancement of a nonmaterial benefit, resulting in an unambiguous reduction in resource use.

Pre-management human societies and nonhuman species engage primarily in the left end, that is, optimal foraging. In resource management societies, humans also make material tradeoffs-hence, we see marginal decisionmaking as a cornerstone of microeconomic theory. But when humans manage themselves and their resource use, they reduce consumption 
THOMAS PRINCEN

FIGURE 1. Substitution vs restraint.

Material $\underset{\text { Substitution }}{\stackrel{\text { BENEFITS }}{\longrightarrow}}$

now to reap rewards later. This, too, is consistent with the logic of microeconomics and market behavior (eg., investment and time discounting). Restraint enters, and economic reasoning generally departs, when material benefits are traded for nonmaterial benefits: social acceptance, self-reliance, economic security, personal health, family wellbeing, political independence, a sense of competence and achievement, artistic expression, religious and aesthetic experience.

From a utility theory perspective, the tradeoff associated with restraint is rational and, in some sense, "economic." Individuals maximize their utility by optimally selecting from a basket of material and nonmaterial goods. What economic theory tends not to do, however, is to separate the tradeoffs in this optimization. It tends to see all goods as substitutable and all tradeoffs as possible, subject to budget and institutional constraints. Moreover, for policy purposes, the uses of economic reasoning tend to emphasize the material. Growth in measurable benefits, that is, material goods, prevails in policy making at all levels of industrial and industrializing societies. To be sure, the economic development literature tries to incorporate nonmaterial values. But, in practice, the logic is generally the same: increases in material wealth are necessary before increases in other benefits-"leisure" or a safe work place or a clean environment-can be realized.

By contrast, my emphasis on reduced material consumption in exchange for nonmaterial benefits attempts to capture a range of behaviors that do not follow the prevailing logic. People do volunteer their labor, organize their communities, serve their country in the military, and donate to charities whether or not they have achieved high levels of income and whether or not they expect future material rewards. Restraint, as defined here, is precisely that choice of non-material over material goods, in both the near and far term. Put differently, it is that choice whereby the effect is to elevate non-resource consuming activities above resource consuming activities. From an ecological and, ultimately, social perspective, resource consumption that falls within regenerative and assimilative capacities is a superior form of consumption. Contrary to the prevailing economic reasoning, not all consumption is alike and certainly infinitely increasing rates of 
material consumption are thermodynamically and ecologically impossible (Ehrlich, Ehrlich, \& Holdren, 1993; Georgescu-Roegen, 1993).

One might argue that even here, such restraint leads to future material consumption, much as investment does. But the point here is that investment for future consumption does not capture all observed behavior, especially that relevant to reduced or limited consumption. Investment, as used in economic accounting, ignores the material/nonmaterial tradeoff humans make and, as is well known, it ignores ecological impacts. The mechanism of restraint, unlike substitution and investment, raises questions not generally raised in the economic, business, or even environmental communities. As such, it is policy relevant because it offers opportunities for adaptation to contemporary problems different from those typically coming out of the policy community, that is, recommendations to adjust current patterns of consumption. Restraint directs analytic and policymaking attention away from, say, environmental protection and preservation and the greening of industry, and toward those conditions that foster nonmaterial "consumption." The analytic challenge, consequently, is to identify those conditions under which this subset of behavior is dominant, not subsidiary, as in the contemporary political economy. I return to some of these conditions below after considering the second way restraint can be driven, namely, social norms.

In contrast with economic choices, social norms show the most promise of durable adaptation over the long term, both psychologically and institutionally (De Young, 1993; Katsev \& Johnson, 1987; Ostrom, 1990; Young, 1989). Absent crisis, they may also be the most difficult to implement in the face of a dominant belief system-namely, technologically driven economic growth.

Socially, an individual who demonstrates restraint sends a signal to others that he or she is committed to the group. This is especially true in small, tightly integrated groups. If I restrain my overall consumption, more is available for others. Through restraint, I can develop a reputation for cooperation, assuring others that group participation is rewarded. Also, with such a reputation, monitoring and enforcement within the group are easier. This both strengthens group activity and allows for increased individual autonomy because elaborate control mechanisms are not needed.

When reputations develop around a mutually rewarding behavior like restraint, that behavior becomes a norm. Through cultural adaptation, the norm of restraint provides individuals a clear and easily used vehicle for demonstrating group loyalty and dependability. And restraint as a norm is particularly easy to employ because the individual need only refrain from doing something. Of course, it is this very ease of use (not doing some- 
THOMAS PRINCEN

thing) that makes it difficult for outsiders to observe which may explain in part why it has received so little analytic attention. ${ }^{2}$

Strictly speaking, of course, restraint is difficult to observe. But from the perspective of longterm resource management, the behavior can be interpreted as a substitute for effective feedback between the resource and its consumption. As discussed below, because feedback in a managed resource system entails temporal lags and spacial distances far greater than that in a nonmanaged system, surrogate behaviors will evolve from preexisting behaviors. Visible, clearly communicated restraint may be one such behavior. It is fundamentally conservative with respect to pushing the resource beyond regeneration when feedback is ineffective.

\section{THE EVOLUTION OF RESTRAINT-AN HYPOTHESIS}

From an evolutionary perspective, a tradeoff between material and nonmaterial benefits may enhance individual survival and reproduction and thus will be selected for. To demonstrate an evolutionary (genetic and cultural) basis for restraint in resource consumption, it is necessary to identify precursors and trace adaptations from hunter/gatherer societies through contemporary industrial and post-industrial societies. The following posits how that history might have occurred where each proposition is intended only as a testable hypothesis.

Hunter/gatherers exercise restraint with respect to members of their group. They restrain their aggressive/defensive tendencies and they restrain their consumption of resources when others participate in the acquisition of those resources and when group cohesion depends on the sharing of those resources. This can be considered a limited form of resource restraint as it can be relaxed whenever there is abundance. Also, it is not a very demanding form of restraint because it has immediate feedback mechanisms. Investment in a group hunt, for example, leads to immediate rewards for the individual and kin. An occasional solo hunt would confirm the advantages of group hunting and, concomitantly, individual restraint, at least enough to keep the group together. This kind of restraint also is limited because it need be exercised no further than the group, certainly not extended to the environment. Thus, if a given resource is exhausted, the group merely moves on to the next. it is the inability or unwillingness to move on, however, that contributes to the transition to agriculture and to selective pressures for extended forms of restraint.

With agriculture and, eventually, industry, restraint must be extended over time. Seeds must be saved, shoots and fruits must be allowed to ma- 
ture. Restraint becomes adaptive because the inherent time lags between the initial investment of effort and materials and the eventual consumption of the output weakens the feedback from the resource and its regenerative capacity, on the one hand, and to patterns of resource use, on the other. Successful adaptations in the transition from hunter/gatherer to agriculture were likely to be those that 1) restored or recreated effective feedback mechanisms; and 2) built on previously successful behaviors, including social and resource restraint. One strategy would likely have been group or collective management.

That is, successful adaptation would have been, first, to forego the immediacy of returns on investment (i.e., until harvest) if members of the group could be assured others in the group would so restrain their use. The assurance problem (Runge, 1992) thus becomes a driving force in the shift from hunter/gatherer to agricultural society. Its resolution may have provided the critical replacement for resource feedback. This hypothesis suggests that successful solvers of this problem were those groups who developed two strategies:

1) Group-based, self-management mechanisms that more-or-less correspond to principles of effective common property management as delineated by Ostrom (1990).

These principles show how local sustainable use can occur. Ostrom's eight principles are: clearly defined boundaries, congruence between the rules of resource use and local conditions, participation by the users in changing the rules, monitoring, graduated sanctions, conflict resolution mechanisms, rights to organize, and organization of all activities within a larger institutional context.

2) Self-defense mechanisms that not only draw boundaries around resources and exclude others but also internalize benefits, externalize costs, and open others' resource boundaries.

These mechanisms can account in part for the success in material and power terms of some societies and of some members of societies-eg., imperialists, colonialists, pioneers, traders, transnational capitalists-and the relative failure of others. These mechanisms account for both self-management and environmental degradation through cost externalization and the creation of open-access property regimes (Bromley, 1992; The Ecologist, 1992). From a longterm perspective, however, such success may be only short term since they depend on unending increases in throughput and on technological innovation to handle all problems that result (Daly \& Cobb, 1989; Ehrlich \& Ehrlich, 1990; Meadows, Meadows, \& Randers, 1992; Pirages, 1989). In other words, these mechanisms point to the unsus- 
THOMAS PRINCEN

tainability of many such strategies when resources are exhausted and waste sinks filled-i.e., the conditions of global ecological crisis. ${ }^{3}$

For prescriptive purposes, therefore, strategies 1) and 2) can help explain both durable resource use and environmental degradation. The two strategies can also suggest the kind of adaptation in consumption behavior needed to reverse the trends in this crisis. That is, they suggest how adaptation of existing behavioral tendencies, as opposed to creating evolutionarily novel ones (Low \& Heinen, 1993), can take place.

One adaptation, put simply, is to draw boundaries around critical resources, exclude others, and defend against intrusions-what I will call resistance. Such an adaptation enables groups to resist temptations, especially those that entail what can be characterized as asymmetrical and Faustian bargains. When a transnational timber company negotiates with a group of forest peoples, the bargain is asymmetrical in the information, technology, and economic alternative to agreement held by each of the parties. When a hazardous waste shipper contracts with a desperately poor farmer to store barrels of unknown chemical mixtures, the bargain over time and across generations is Faustian. Resistance thus serves as a counterweight, or counterstrategy, to the attempts of others to employ the second strategy, namely, cost externalization and the opening of other's boundaries. It is, of course, true that few groups in the last several centuries have been successful in simultaneously managing their resources and resisting the intrusions of others, especially when those intrusions are accompanied by force and the promises of great wealth. In recent years, however, examples of such efforts appear to have increased. Successful groups appear to be those who not only resist locally but establish political linkages internationally. Indigenous peoples have blocked dams and logging operations while international nongovernmental organizations (NCOs) and intergovernmental organizations have put pressure on governmental and private funders (Korten, 1990; Rich, 1994). In general, the analytic and communicative skills of peoples at all levels of society worldwide are increasing (Rosenau, 1990) and transnational linkages are enabling previously exploited peoples to manage their own resources (Princen \& Finger, 1994).

The important analytic point, however, is that these efforts are distinguished from political or religious resistance. They are not mass rebellion against a dominant authority nor are they localized efforts to exclude the outsider. Rather, as a resource management adaptation, these efforts necessarily compel the resource users to restrain the use of their own resource. Users cannot risk pushing the resource beyond its regenerative capacity 
POPULATION AND ENVIRONMENT

because the success of the adaptation depends not on cost externalization or on opening others' boundaries, but on managing one's own resource. That resource thus becomes "close," just as all things do that we are highly dependent on-parents, children, job (if alternatives are few), neighbors (if there is a sense of community), car (if rare or restored). The resource being closer, we are risk averse in its exploitation. As a result, we build in a cushion against lean times. We encourage organizational and managerial buffer through our group's internal self-organization and through our influence on the external institutional environment. ${ }^{4}$

In short, through self management we resist intrusions into our resource and restrain our use to allow for the unpredictable and the variable, for the low probability, yet high cost event. Put differently, the nonmarket, nonmaterial value of resource dependability and security over time overshadows the potential short-term, material gains. Discount rates for my own, self-managed resource are low. By contrast, my discount rate for your group's resource is relatively high. All else equal, if you give me access, even at a supposedly "fair" price, I am more likely to degrade it than you are. Restraint and resistance are key behaviors, therefore, in a sustainable economy. With this hypothesis of an evolutionary basis to restraint and the choices of self-management and resistance as strategies, I now turn to the conditions for actually promoting such behavior.

\section{SUFFICIENCY AND THE CONDITIONS FOR RESTRAINT}

Many societies define progress as increasing material consumption (Figure 2). The notion has intuitive appeal because, as individuals, we do consume more as we grow larger and, as societies, we consume more as we collectively provide our necessities and self-defense. The notion also has an evolutionary or adaptive appeal as it is well established that preliterate humans and nonhuman species enjoy reproductive success when they acquire more resources, even if those resources only contribute to status and prestige (Low \& Heinen, 1993).

In a world of unlimited resource availability and waste sink capacity, this notion has been not only intuitively and adaptively plausible, it has been a driving force in industrialization, capitalist and socialist, and expanding markets generally (Daly, 1991). For many practical purposes, such a world did exist. There was always a frontier. One could extract resources and dump wastes and no one (or no one of consequence to the extractors and dumpers) bore the burden.

It is now well known that, for most practical purposes, such a world 
FIGURE 2. Progress as increasing consumption.

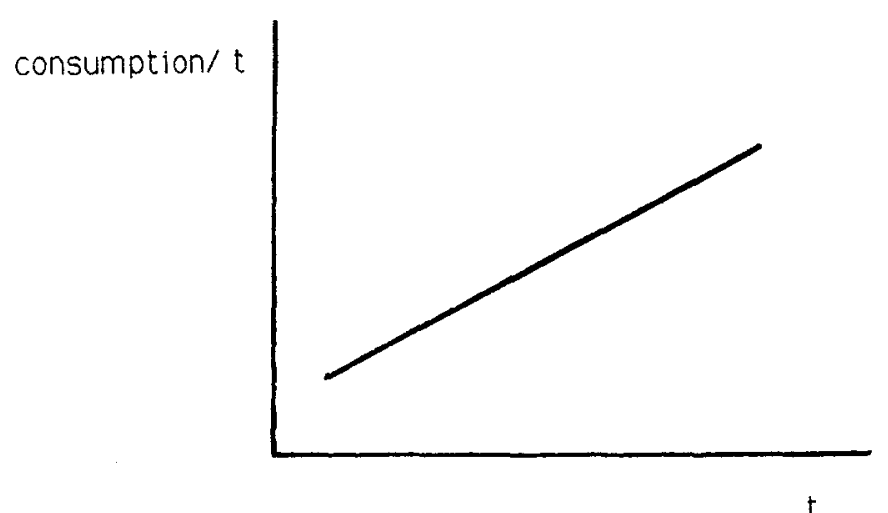

no longer exists. But what is generally not widely recognized, and what may be a more important observation from a sustainability perspective, is that, because ecological constraint has existed side-by-side with the frontier, humans have long dealt with, and adapted to, resource limits. As a consequence they have developed mechanisms, mostly through cultural evolution, to restrain their resource use, as hypothesized above. Restraint is not, in other words, an evolutionarily novel behavior. It may have been relegated to an inferior status when progress was defined in terms of increasing material consumption. But it is at least as "natural" in post-hunter/ gatherer societies as unbridled consumption.

To set the conditions for restraint, I put the concept in the larger context of sufficiency, that is, the point at which a resource user decides that a level of consumption is enough. Sufficiency does not define a sustainable level of resource use. It can, however, be a target for policy makers and collective resource users. The premise here is that if sustainable levels have to be calculated and then enforced through external incentives, both the complexity of the task and the unlikelihood of its implementation will render the goal of sustainability unachievable. Sufficiency as a target or direction has, I argue, a better chance of adoption at the individual, group, and, eventually, societal levels.

\section{Sufficiency}

Decision makers, whether as individuals or as organized collectivities, strive to increase material consumption over an initial period. Children eat 
POPULATION AND ENVIRONMENT

FIGURE 3. Sufficiency.

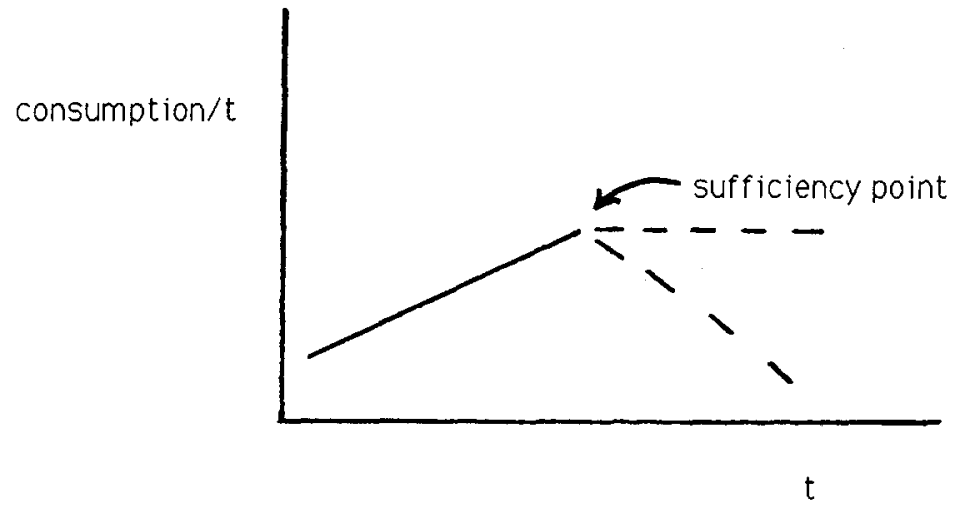

more and more food and industrializing countries burn more and more fossil fuels. For some decisionmakers and for some resources, such consumption eventually levels off or even drops. This turning point may be due to a simple inability to consume at higher rates (obese people cannot increase their rate forever) or to better returns from the consumption of an alternative resource (from coal to natural gas, for example).

The turning point may also be due to a decision to pursue a nonmaterial benefit. I will call this a sufficiency point (see Figure 3). If the fullgrown youth refuses the next increment of food consumption and instead chooses an additional increment of music practice, that individual has reached sufficiency in food consumption. If a nation decides to forego the next level of consumer goods to increase taxes and train its citizenry in civil defense, that society has reached a sufficiency point in consumer goods.

In principle, if sufficiency is reached on all critical resources and the associated level is regenerative, a sustainable economy is achieved. But I take as axiomatic that sustainability can only be a high-level goal. To be operational, objectives must be identified and their behavioral assumptions made explicit. Sustainability is the general goal, then, and sufficiency the objective (Lele, 1991). Sufficiency, restraint, self-management, and resistance provide the behavioral underpinnings, then, of policies and institutional mechanisms aimed at sustainability. What, then, are the conditions that encourage such behaviors?

\section{Conditions}

Restraint is the behavior that determines the sufficiency point and that maintains the reduced level of consumption over time. It is a function of 
two sets of factors, the first of which includes information, innate or learned preferences, and external incentives. Although these capture many popular approaches to environmental problems, they also appear least amenable to effective policy interventions to reduce consumption.

Lack of information regarding environmental impacts underlies the rationale for much of environmental education, formal and informal. Examples of successful environmental policies resulting from enhanced environmental awareness include the U.S. bans on DDT and PCBs (owing largely to Rachel Carson's Silent Spring) and reduced CFC production after consumer rejection of household aerosols (owing largely to an intense media campaign). Despite these and other successes, many in the environmental movement now believe that more information and improved public awareness is not enough to arrest current trends. Soil erosion and rainforest destruction are well documented and well known, including by those who contribute to such destruction, but the trends continue (Colchester \& Lohman, 1993; Myers, 1993; Brown, Lenssen, \& Kane, 1995).

Preference for nonmaterial goods can be learned which suggests avenues for intervention. But as with public awareness, individual attitude change is difficult, slow, and sensitive to exogenous shocks, especially an opportunity for new-found wealth or a possibility that personal wealth will decline. It is also doubtful that effective attitude change programs can be implemented on a global basis and in time to deal with urgent problems. This is especially true where major segments of a society live at a subsistence level.

External incentives include economic and religious factors. Economic incentives can lead to behavior change but the effects of tax credits and pollution fines often do not last. When the incentive is removed, previous behaviors tend to recur, all else equal (De Young, 1993; Katsev \& Johnson, 1987). Religious sanction may be more long-lasting but the impact minor. Pope John Paul II's anti-consumerist calls are probably heeded, if at all, only by the clergy and a few devout, obedient, and economically secure Catholics. ${ }^{5}$

Information, learning, and external incentives all play a part in an overall social change process aimed at sustainability. But they all fly in the face of powerful social forces, especially those that champion economic growth and material consumption. Moreover, as practiced, environmental education, environmental policymaking, and the economic stance of major religions all tend to support, even promote, such forces. Environmental education dwells on nature appreciation, environmental policies emphasize end-of-the-pipe remediation and clean-up, and religions support the economic policies and the hoped-for prosperity and support of their host states. 
Despite my cursory treatment and possibly facile dismissal of this first set of factors, it does appear that they have significant weaknesses and that examination of factors more directly tied to economic choices and ecological constraints is necessary. The second set of factors thus includes ecological feedback, institutional arrangements, and economic security.

Ecological feedback refers to the negative signals an organism receives when it disturbs its environment. Such feedback leads to changed behavior, at least in the short term. With respect to resource use, when the feedback tells the organism that depletion is imminent, it finds alternative resources via extended foraging or migration. Humans also pursue technology innovation and modify their behavior by, for example, adopting soil conservation methods when crop yields decline. If such feedback is interrupted or cannot be assimilated or is subject to collective action problems (i.e., an inability to overcome individual incentives to achieve collective benefits), the behavior is unlikely to change and the resource is likely to be pushed to depletion.

Effective feedback from one's resource consuming behavior to that behavior's environmental impact is a precondition for restraint. Education, coercion, and incentive systems are not necessary to restrain resource consumption when clear signals are coming from the resource itself and when, as a result, those signals portend risks to the user's wealth or economic security or survival. Self-interest, although not the only motivator, remains the most powerful.

Institutional arrangements leading to restraint have both endogenous and exogenous components. Resource management schemes in both private and common property regimes (and, for that matter, state property regimes) are typically successful only when users can draw boundaries around the resource and exclude others, as discussed. To do this, an external political environment that ensures those property rights and, hence, the longterm flow of benefits, is necessary. Here is where policy interventions are most likely to be effective. The implied policies would put a priority on secure property rights, whether private, common or state held, rather than on opening markets, subsidizing transportation, and promoting privatization and deregulation.

Economic security complements institutional arrangements. Studies of soil erosion and conservation find that farmers worldwide will knowingly overuse their land when prices are highly uncertain, when market conditions create extreme competition, or when suppliers and buyers have significant market power. Control over these factors increases as farmers form cooperatives, sell their products directly to consumers, generate their own fertilizers, develop their own pest controls, and increase their household 
THOMAS PRINCEN

self-reliance (Dahlberg, 1993; Kneen, 1989). All these self-management measures increase economic security and, as a secondary effect, entail less production per acre. This, then, is restraint motivated not by enhanced information or guilt or external incentives but by the pursuit of self-interest in a non-material value-economic security-rather than a material value which necessitates ever-increasing material use.

Of the several conditions for restraint, those grounded in self-interest and economic security appear to offer the most promise. From a prescriptive perspective, they exploit existing behavioral patterns, not evolutionarily novel ones, to promote reduced or limited resource consumption. On the face of it, however, self-interest and economic security may appear to be behaviors contradictory to the goal of reduced consumption. The apparent contradiction, however, is analogous to what international relations theorists have done to explain cooperation.

\section{PARADIGMATIC SHIFT: FROM REDUCED CONSUMPTION TO RESTRAINT IN CONSUMPTION}

The long-standing dichotomy between realism and idealism in international relations theory has existed in part because realism could not account for cooperation among self-interested states. The theoretical advances of Axelrod (1984), Oye (1986), Keohane (1984) and others was to employ the same behavioral assumptions of realists and, through logic and stylized games, get cooperation.

In the environmental realm, a parallel dichotomy has existed, that between what I will call consumerism and environmentalism (see Figure 4). ${ }^{6}$ Consumerism is part of two dominant theoretical approaches to human and nonhuman behavior, namely economics and behavioral ecology. Significant strands of thought within political science, anthropology, sociology and other disciplines are influenced by this paradigm.

Consumerism holds that individuals will maximize their utility or survivability and reproductive success by optimally choosing among an array of resources. Investment of time and possessed resources is aimed at the maximization of present and future resource consumption. Variations allow

FIGURE 4. The realist-consumerist parallel.

Realism vs Idealism $\rightarrow$ Cooperation

Consumerism vs Environmentalism $\rightarrow$ Restraint 
for reduction in uncertainty as a primary goal. But, in general, these approaches emphasize the consumption of resources. Other goals such as self-esteem or community or spirituality or even economic security (as opposed to economic wealth) are relegated to the black box of "utility" or to other disciplines such as psychology.

In these models of behavior, the only reason to withhold consumption of one item is to increase the consumption of another. Substitution fits but restraint in overall material resource consumption is out of the realm of the consumerist paradigm. And in applied settings, restraint is not only out of the realm of the dominant paradigm, it is anathema to certain tenets of modern life, namely growth, efficiency, specialization, mobility, and competition. As I have argued, however, restraint is not a novel behavior. In industrial and post-industrial societies, it only has been relegated to the ascetic, the fringe, or the quaint. In contrast to consumerism, environmentalism holds that, by consuming minimally, consumers will (or should) increase their satisfaction and ensure the longterm survivability of their society and the planet. Protecting natural areas, recycling, and using mass transit are activities consistent with this paradigm.

The parallels between the realist/idealist dichotomy and the consumerist/environmentalist dichotomy are several. Realism and consumerism emphasize self-interest, individualism, short-term calculation, and rational choice. Idealism and environmentalism emphasize other-interestedness, social goals, and longterm calculation. Moreover, just as realism could not explain extant cooperation among self-interested actors, consumerism cannot explain extant restraint in resource consumption. Similarly, just as idealism cannot explain cooperation without resort to normative arguments (one should cooperate for the greater good, we must cooperate to ensure peace), environmentalism cannot explain restraint without comparable resort (one must consume less of the Earth's resources, we must cooperate to overcome our greedy tendencies).

The realist/idealist dichotomy was resolved by focussing on cooperation. Under certain conditions such as repeated plays and a long shadow of the future, egoistic actors could rationally cooperate not because they converted to peace-loving, global citizens but because it was in their own self-interest; their national security, for example, would be enhanced. Similarly, then, we need not demand or expect consumers to convert to environmentalism. Rather, under certain conditions, some of which are posited above, these materially growth-oriented individuals will find it in their own self-interest to restrain their material consumption as a means of attaining higher nonmaterial goals, one of which is economic security. 
In sum, a focus on material restraint rather than on environmental conversion has parallels with the international relations community's focus on cooperation rather than on, say, hegemonic stability, international law, or international organization. That community's conceptual advance has led to policy prescriptions that do not rely on the diminution of national security concerns or on the promise of some form of world government. Similarly, the sustainability community needs concepts to build and adapt existing human behaviors and the institutions that support them. Such concepts might include restraint, self-management, resistance and sufficiency.

\section{ADVANTAGES OF THE FOCUS ON RESTRAINT}

The concept of restraint, as opposed to cooperation, efficiency seeking, recycling and other behaviors generally assumed necessary to reverse environmental degradation, has several advantages for addressing critical environmental issues.

1) It makes explicit the ecological difference between material and nonmaterial consumption. From a conventional economic perspective, all goods, material and nonmaterial, are substitutable. From an ecological perspective, substitutability cannot be assumed when the resource is an aquifer, a layer of topsoil, a degree of biodiversity that allows for regeneration, a stratospheric layer of ozone that shields all life from ultraviolet (UV) radiation, or an entire atmosphere that moderates climate. At the same time that the concept of restraint distinguishes material and nonmaterial consumption, it does not preclude tradeoffs. It merely helps direct our attention to those tradeoffs that have either near-term or longterm effects.

2.) Restraint does not assume that individuals will, contrary to their evolutionary history, adopt a very longterm-i.e., ecologically longtermperspective. It merely assumes that humans will restrain their near-term consumption in exchange for (relatively) near-term nonmaterial benefits. In so doing, the reduced consumption decreases the likelihood of ecological overshoot. It has a longterm effect, yet not because practitioners become global citizens or because they adopt extremely low discount rates. Rather, they seek other values, including that nebulous, but powerfully motivating, "sense of security" by reducing consumption. As a consequence, in the aggregate and over time, the effect is, indeed, to reduce a society's consumption.

3) At the individual level, restraint implies a potentially positive tradeoff between material and nonmaterial goods. The environmentalist call for 
reduced consumption, by contrast, implies a reduction in satisfaction in exchange for some ill-defined, possibly unreachable general goal of, say, planetary salvation. What is more, from a collective action perspective, reduced consumption is readily seen by the individual (or any unit including states) as the sucker's pay-off in a multiperson, Prisoner's Dilemma.

4) At the organizational level, restraint is more consistent with the resource implications of self-organization and self-governance. Ostrom (1990), Bromley (1992) and others, for example, have found that common pool resources can be successfully managed for decades, even centuries, when certain conditions are met by self-organizing, self-managing groups of resource users. This resource behavior is not well captured by altruism or conservation. Cooperation is insufficient as well because other organizations - transnational corporations, the World Bank, and so forth-are also very cooperative but it is cooperation to increase consumption, not limit it. Restraint best captures the specific behavior of the self-organized common pool users because the users themselves agree to use less than they would individually want and agree to self-imposed monitoring and penalties.

5) At the collective, societal level, a focus on restraint encourages the intervenor and the policy maker to look for mechanisms that reward nonmaterial activities. These may include participation in community-based education and policing, self-reliance by producing one's own shelter and food, and voluntary service at the community, national or international levels. Such activities are widely seen to strengthen communities at many levels. Yet policy makers need justification to promote such activities because they contradict commercial and employment policies aimed at economic growth for which increased consumption is integral. Restraint offers these decision makers a recognizable but non-altruistic alternative.

6) Restraint may be the only behavior that provides the necessary ecological feedback between resource consumption patterns on the one hand, and resource regenerative and assimilative capacity on the other. Human societies have created so much distance between production and consumption decisions that it is virtually impossible to relate one's individual decisions to collective and environmental impacts. On cognitive grounds, we cannot possibly collect and process the necessary information. And on ethical grounds, we cannot assume responsibility for a host of decisions that, for example, bring grapes and flowers from Chile to North American supermarkets in winter.' Restraint compels individuals and societies to reduce that distance, increasing the likelihood that consumption decisions will be related to production decisions and, hence, to ecological impacts. 
THOMAS PRINCEN

\section{ENDNOTES}

1. Restraint within a private, profit-making, growth-oriented corporation may appear contradictory. But as economist Robert Heilbroner (1956) stresses in his history of industrial development and the desire for gain, one of the great paradoxes of capitalism is that the capitalist must be thrifty. Unlike all previous means of acquiring wealth (conquest and marriage, primarily) the capitalist does not indulge himself with his newfound riches, but reinvests it to generate yet more wealth.

2. The other major reason is that it contradicts a fundamental tenet of modern, industrial society-growth, especially growth in material goods.

3. By "global" 1 do not mean strictly those issues that span the planet, i.e., global warming, ozone depletion, and loss of biodiversity. Rather, I refer to those issues for which displacement of costs across media and over time and space are no longer tenable for both ecological and social reasons.

4. Evidence of such buffers can be found in the common property regime literature (eg., Bromley, 1992; Ostrom, 1989) although they are often referred to as "inefficiencies." In fact, what from an outsider's perspective appears to be inefficiencies is, from inside a successfully managed commons, often a useful and necessary cushion (personal communication, Fikrets Birkes, 1995).

5. This is not to say that the pope and other religious figures are not important shapers of public opinion. But in the face of mass advertising and the reverence for consumption and entertainment that prevails among so many in the U.S. and elsewhere, it is doubtful that on this count they have had much influence.

6. Both these terms, consumerism and environmentalism, are somewhat unfortunate because they are widely used in other contexts. Consumerism often refers to the movement among consumers to expose shoddy goods and improve consumers' decision making. Environmentalism usually refers to the entire set of movements from nature protection to pollution control to sustainable development. Although the terms have these other connotations, I choose them in lieu of creating terms de novo. Their analytic utility rests on the precision of the definitions, their consistency of use, and, most important, the extent to which they offer new conceptual perspectives.

7. LaRue Hosmer, personal communication, 1994.

\section{REFERENCES}

Alcorn, Janis B. \& Toledo, Victor M. (May, 1995). The role of tenurial shells in ecological sustainability: Property rights and natural resource management in Mexico. Paper presented at annual meeting of International Association of the Study of Common Property, Bodo, Norway.

Axelrod, Robert (1984). The evolution of cooperation. New York: Basic Books.

Bromley, Daniel W. (1992). (Ed.). Making the commons work: Theory, practice, and policy. San Francisco, CA: Institute for Contemporary Studies Press.

Colchester, Marcus \& Lohman, Larry (1993). (Ed.). The struggle for land and the fate of the forests. London: Zed Books.

Dahlberg, Kenneth A. (1993). Regenerative food systems: Broadening the scope and agenda of sustainability. In Patricia Allen, (Ed.). Food for the future: Conditions and contradictions of sustainability. New York: John Wiley.

Daly, Herman E. (1991). Steady-state economics. Washington, DC: Island Press, 2nd ed.

Daly, Herman E. \& Cobb, John B. (1989). For the common good: Redirecting the economy toward community, the environment, and a sustainable future. Boston, MA: Beacon. 


\section{POPULATION AND ENVIRONMENT}

De Young, Raymond. (1993). Changing behavior and making it stick: The conceptualization and management of conservation behavior. Environment and Behavior 25, 485-505.

The Ecologist. (1992). Whose Common Future? A Special Issue. 22, 121-210.

Ehrlich, Paul R. \& Ehrlich, Anne H. (1990). The population explosion. New York: Simon and Schuster.

Ehrlich, Paul R., Ehrlich, Anne H. \& Holdren, John P. (1993). Availability, entropy, and the laws of thermodynamics. In $\mathrm{H}$. Daly (Ed.) Valuing the earth: Economics, ecology, ethics (pp. 69-73). Cambridge, MA: MIT Press.

Georgescu-Roegen, Nicholas (1993). Selections from "Energy and Economic Myths". In H. Daly (Ed.). Valuing the earth: Economics, ecology, ethics (pp. 89-112). Cambridge, MA: MIT Press.

Heilbroner, Robert (1956). The quest for wealth: A study of acquisitive man. New York: Simon and Schuster.

Kaplan, Stephen (1983). A model of human-environment compatibility. Environment and Behavior 15, 311-332.

Katzev, R.D. and Johnson, T.R. (1987). Promoting energy conservation: An analysis of behavioral research. Boulder: Westview Press.

Keohane, Robert O. (1984) After hegemony: Cooperation and discord in the world political economy. Princeton: Princeton University Press.

Kneen, Brewster (1989). From land to mouth: Understanding the food system. Toronto: NC Press.

Korten, David C. (1990). Getting to the 21st century: Voluntary action and the global agenda. West Hartford, Conn.: Kumarian Press.

Lele, Sharachchandra M. (1991). Sustainable development: A critical review. World Development 19, 607-21.

Low, Bobbi S. \& Heinen, Joel T. (1993). Population, resources, and environment: Implications of human behavioral ecology for conservation. Population and Environment 15, 7-41.

Meadows, Donella H., Meadows, Dennis L. and Randers, Jorgen (1992). Beyond the limits: Confronting global collapse, envisioning a sustainable future. Post Mills, Vermont: Chelsea Green.

Myers, Norman (1993). Ultimate security: The environmental basis of political stability. New York: W.W. Norton.

Olson, Mancur (1965). The logic of collective action: Public goods and the theory of groups. Cambridge, MA: Harvard University Press.

Ostrom, Elinor (1990). Governing the commons: The evolution of institutions for collective action. Cambridge: Cambridge University Press.

Oye, Kenneth A. (1986). ( Ed.). Cooperation under anarchy: Princeton: Princeton University Press.

Pirages, Dennis (1989). Clobal technopolitics: The international politics of technology and resources. Pacific Grove, CA: Brooks/Cole.

Poore, Duncan (1989). No timber without trees: Sustainability in the tropical forest. London: Earthscan.

Princen, Thomas \& Finger, Matthias (1994). Environmental NGOs in world politics: Linking the local and the global. London: Routledge.

Rich, Bruce (1994). Mortgaging the earth: The world bank, environmental impoverishment, and the crisis of development. Boston: Beacon Press.

Rosenau, James (1990). Turbulence in world politics: $A$ theory of change and continuity. Princeton: Princeton University Press.

Runge, C. Ford (1992). Common property and collective action in economic development. In Daniel W. Bromley (Ed.) Making the commons work: Theory, practice, and policy ( $\mathrm{pp}$. 17-39). San Francisco: Institute for Contemporary Studies Press.

Stern, Paul C. (February 15, 1993). The second environmental science: Human-environment interactions. Lecture, annual meeting, American Association for the Advancement of Science, Boston.

Young, Oran R. (1989). International cooperation: Building regimes for natural resources and the environment. Ithaca, NY: Cornell University Press. 